\title{
Das técnicas ilusionísticas à tecnologia do abismo
}

\author{
Daniel Tércio
}

'Thecla Schiphorst é uma artista multimédia,

actualmente a trabalhar na Universidade Simon Fraser, em Vancouver, Canadá. Tem formação no

dominio das artes performativas, como coreógrafa e bailarina, e no âmbito da engenharia de sistemas informáticos. Integrou a equipa original

que desenvolveu o software Life Forms, a ferramenta informática a que Merce Cunningham mais recorreu, e colaborou com este criador a partir de 1990.

Cf.http://www.sfu.cal $\sim$ tschipho/.

${ }^{2}$ Sobre análises da relação da tecnologia com as artes performativas, sobretudo na actualidade, ver Giannachi (2004) e o estudo monumental de Dixon (2007).

Daniel Tércio é Professor da

Faculdade de

Motricidade Humana da Universidade Técnica de Lisboa e crítico de dança do jornal Expresso.
Há algumas semanas traduzi para português um texto intitulado "Body Noise: Subtexts of Computer and Dance", publicado por Thecla Schiphorst na revista Computer Graphics, em 1997'. Neste artigo, Schiphorst toma posição acerca da relação entre a tecnologia e o corpo. Contrariamente à atitude de disembodiment, perspectiva adoptada pela tecno-cultura dos anos 1990, e que veicula a ideia de corpo-descartável e de corpo-residuo, a autora propõe a ideia de incorporação da tecnologia, defendendo militantemente o corpo na centralidade da comunicação humana. Schiphorst argumenta que a inteligência corporal precede os recursos tecnológicos - existindo, pois, primeiro do que todas as aparelhagens analógicas ou digitais com que lidamos - e que a nossa própria experiência física pode ser expandida tecnologicamente, mas jamais substituida pela tecnologia (Schiphorst 1997).

Em que é que a técnica e a tecnologia - e o texto de Schiphorst - se articulam com a relação entre corpos performativos e práticas cénicas? A minha resposta a esta questão está longe de pretender esgotar toda a complexidade implícita na pergunta. Assim, optei deliberadamente por estreitar os dados do problema, definindo-o a partir da relação entre corpo e cena, em dança, entendendo neste caso por cena, antes de mais, os elementos físicos que enquadram e suportam uma interpretação performativa. Neste artigo, a cena é entendida primordialmente enquanto espaço, e a seguir enquanto dispositivo de possibilidades, se quisermos, enquanto organismo tecnológico que autoriza e potencia a performance. Assim sendo - e adoptando com liberdade a formulação de Schiphorst - , o espaço cénico pode ser encarado como um dispositivo para a expansão da inteligência corporal do bailarino-actor.

Este dispositivo não é evidentemente uma entidade estática, nem do ponto de vista diacrónico, nem do ponto de vista sincrónico. De um ponto de vista diacrónico, podemos dizer que as tecnologias de palco se têm transformado ao longo da História ${ }^{2}$, graças entre outros factores à integração de invenções tecno-científicas, tais como a perspectiva linear no século XVI, a luz eléctrica no final do séc. XIX, os sistemas de projecção cinematográfica e videográfica, ou ainda os processos mais recentes de projecção interactiva e a robótica. De um ponto de vista sincrónico, o dispositivo cénico, qualquer que seja a época considerada, apresenta características de interactividade, que o tornam maleável em diferentes graus, tanto quanto são moldáveis os corpos dos performers.

No âmbito do presente artigo, parto da assunção de que a epígrafe "corpos performativos e práticas cénicas" reflecte a relação entre o corpo e o espaço. Assim, proponho que a cena teatral - moldada classicamente como um espaço ilusionístico - se tem transmutado numa estrutura vertiginosa. Esta transformação é particularmente clara em dança, conforme procurarei demonstrar através de uma série de exemplos. A estrutura vertiginosa da cena contemporânea é "escavada" em grande parte graças ao recurso à tecnologia do abismo. Devo prevenir que a utilização destes termos não é inteiramente original já que ambos foram previamente utilizados por exemplo por Virilio e por Boucher, adiante citados. Finalmente, ficará uma pergunta: será que a transformação de "ilusão" para "vertigem" acompanha e protagoniza a deslocação do corpo do bailarino-actor de personagem para performer?

\section{Técnicas ilusionísticas}

A perspectiva linear pode ser considerada não apenas como uma técnica de representação visual, mas também como uma das mais importantes realizações desenvolvidas no âmbito das linguagens cénicas com impacto reconhecido no domínio dos espectáculos teatrais, musicais, operáticos e baléticos.

Na sua génese, a perspectiva anda associada ao modelo do teatro à italiana. A caixa cénica inventada pelos arquitectos do período do "Antigo Regime" surgiu para acolher um novo tipo de espectáculo - nomeadamente o espectáculo operático -, proporcionando também uma nova relação com o público. Distribuir-se-ia este à frente do palco, em plano frontal, condicionando inevitavelmente a direcção da representação. 0 teatro à italiana foi pois uma resposta à solicitação das novas linguagens artísticas. Ao mesmo tempo, este novo modelo, esta "cena de ilusão", contribuiria para redefinir as artes teatrais, condicionando o movimento, o canto e a própria escrita dramática e dramatúrgica. Tal modelo tornar-se-ia assim uma extraordinária máquina capaz de suportar e ampliar a comunicação performativa. A representação em perspectiva, que passou a constituir uma das bases dos aparatos cenográficos, ao reproduzir aproximadamente e por meios artificiais a visão humana, levou a uma ampliação do espaço cénico, simulando a nossa sensação visual de profundidade. 0 espectador passou a ver, não apenas para dentro do palco, mas também para além do pano de fundo do palco. Dentro dessa máquina, e do ponto de vista dos intérpretes, o simples facto de se actuar numa única direcção transformaria radicalmente a linguagem dramática, ao mesmo tempo que, do ponto de vista do público, o acto de espreitar através de uma quarta 


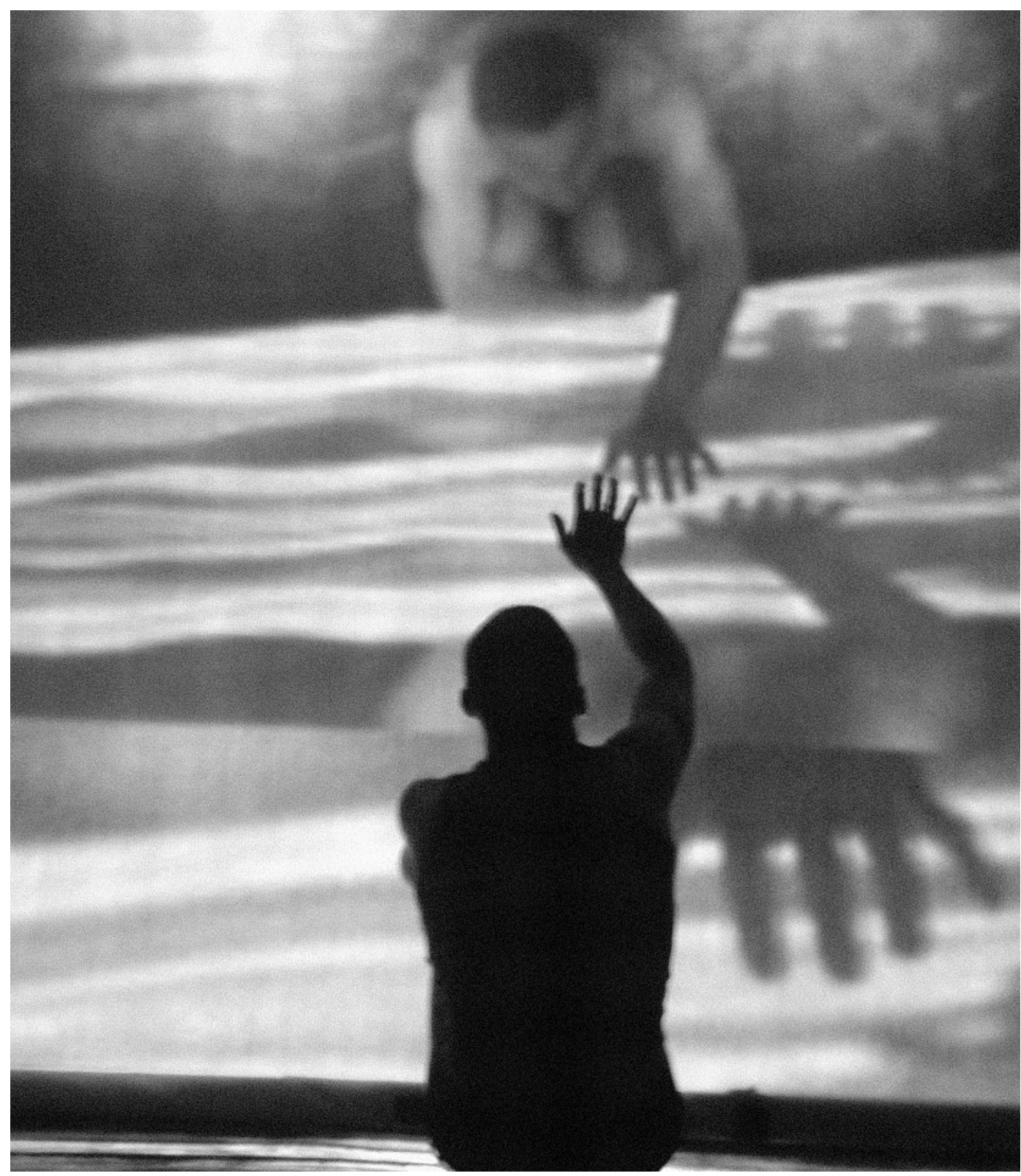

Pixel,

de Rui Horta, ACARTE Centro de Arte Moderna, Lisboa, 2001. parede (aquela que é transparente e desenhada pelo arco do proscénio), combinado com o estabelecimento de um foco do olhar, fixaria um comportamento particular. A cena equilibrava-se, evitando certamente todos os pontos de desequilibrio ou, pelo menos, colocando-os na estrutura rígida dos pontos de fuga da perspectiva linear. 0 palco à italiana, sendo uma imensa máquina, passou a conter e a autorizar novas técnicas, especialmente nos domínios da luz, som, cenografia e figurinos.

No final do século XIX, a electricidade concedeu uma oportunidade para introduzir no palco novos efeitos de luz. Na verdade, iluminar a cena não era nem é apenas tornar visiveis os cenários e as personagens, mas sobretudo sublinhar elementos, deslocando-os entre zonas visíveis e zonas invisíveis, transformar o espaço, moldá-lo à dimensão das personagens. A luz eléctrica adequar-se-ia a esta função. Loïe Fuller, uma bailarina e coreógrafa no princípio do século $X X$, teve um importante papel na utilização deste novo recurso, combinando o efeito dos projectores de luz com filtros coloridos sobre os longos véus de bailarinas ${ }^{3}$. 0 resultado tornou-se extremamente popular na sua época (suscitando toda uma série de imitadoras/continuadoras): as mulheres transformadas em borboletas, rodopiantes, com as suas asas banhadas por luzes coloridas pareciam certamente muito atractivas para o espectador comum. Nos efeitos de luz sobre as asas esvoaçantes destas bailarinas-borboletas adivinhavase já um novo entendimento do espaço cénico, ou, pelo menos, o desejo desse novo espaço.

Seria necessário estudar este novo espaço cénico, sobretudo na relação que estabelecia com o corpo do bailarino-actor. Existe em palco um sistema complexo de linhas e vectores, que condiciona o corpo do intérprete. Oskar Schlemmer, entre outros, reflectiu sobre isto. Ele sabia que o intérprete, ao mover-se, segue os padrões da estrutura espacial preexistente e, ao fazê-lo, cria novas formas - novas dimensões - no espaço. Portanto, o corpo do intérprete tem o poder de produzir espaço. Na verdade e em rigor, os bailados de Schlemmer não apostaram na importação de inovações técnicas; de certo modo, eles foram construídos na linha entre a criação artesanal e a criação industrial, no quadro da Bauhaus. Oskar Schlemmer
${ }^{3}$ A obra coreográfica de Loïe Fuller é referenciada, entre outros, por Isabelle Ginot e Marcelle Michel (2002) e por Julie Townsend (2001). 


$$
\begin{array}{r}
\text { "Cena Trágica", } \\
\text { in De Architectura, } \\
\text { de Sebastiano Serlio } \\
\text { (1475 - c. 1554). }
\end{array}
$$

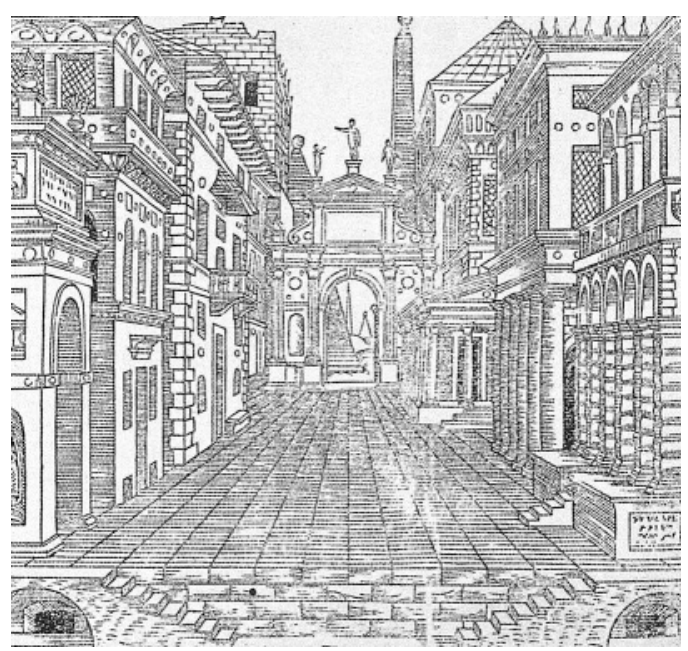

o palco de forma radical. Este adquire, de imediato, um valor cinético ao incorporar em si esta nova forma de representação.

A imagem projectada pode ser encarada como uma mise en abyme visual, um fundo dinâmico (ou, quando é projectada sobre uma cortina de gaze à boca de cena, uma imagem anteposta ao palco), uma nova fonte de luz, ou mesmo um actor, dependendo dos meios, usos e contextos artísticos implicados. (Boucher 2004, tradução minha)

A minha proposta é a de olhar para aquilo que designo por "tecnologias do abismo" na perspectiva plural que atravessa a atitude do grupo da Judson e que marca a pós-modernidade. Assim, e numa tentativa para organizar este terreno, podemos considerar que as "tecnologias do abismo" são atraídas por diversas (mas não necessariamente diferentes) linhas de investigação artistica: (1) desdobramento e detalhe, (2) desmultiplicação de planos e (3) queda e mergulho. Mais do que procurar em cada um deste "atractores" instrumentos tecnológicos típicos (como de certo modo a perspectiva linear o foi para a tecnologia anterior), importa perceber como eles se articulam na construção de novas linguagens.

\section{(1) Desdobramento e detalhe}

Philippe Decouflé, que foi aluno de Alwin Nikolais, herdou deste uma notável plasticidade do movimento, integrando as linguagens circenses e a intenção de construir universos efabulatórios; a obra de Decouflé revela uma escrita coreográfica de micro-gestos, como por exemplo em Le P'tit Bal (1994), uma coreografia para cinema, e em de Marselha, que traz para o palco criaturas bizarras, procedendo a transferências de escala ${ }^{4}$. A camcorder é em alguns momentos usada para captar o detalhe e para duplicar elementos cénicos e corporais, proporcionando a revelação labirintica da existência.

Num registo mais íntimo, há que recordar as peças do criador português Rui Horta, nomeadamente Pixel (2001) e Scope (2007) $)^{5}$. A primeira peça desmultiplica o espaço cénico numa sucessão de planos em que o(s) intérprete(s) se rebate(m); o palco funciona como que sobre a construção mecânica dos diferentes planos da perspectiva renascentista, mas agora implantados como possibilidade infinita de rebatimento, em que o espectador é também envolvido, através do manuseamento de uma câmara de filmar. Quanto a Scope, trata-se de uma peça construida envolvidos numa história passional, e um aparato técnico

${ }^{4}$ V. http://www.cie-
} espaço dramático. A este respeito, Marc ucher escreveu:

\footnotetext{
um lugar comum. Os efeitos espectaculares que oferece são hoje aceites como naturais, e mesmo os mais subtis não são sequer discutidos. Imagens em movimento, quando projectadas, transformam

0 uso de imagens projectadas em cena tornou-se, em pouco tempo
} Decodex (1995), apresentado pela primeira vez no festival com duas personagens, um homem e uma mulher

conduziu a sua investigação separando o corpo do intérprete experiências radicais, adoptando novos palcos, orquinos em lugares para apresentações performativas.

Entretanto, na segunda metade do século XX a utilização de projecções cinematográficas e videográficas em cena tornava-se frequente, suscitando uma nova

\section{Tecnologia do abismo
Para a utilização em palco daquilo que designo por} diz respeito, não apenas a adopção pelo campo da arte de técnicas sem tradição "artística" - como aconteceu, por John Cage e os objectos de raios catódicos de Nam June Paik nos anos 1950 e 1960 -, mas também o experimentalismo valor do detalhe e da repetição, que está intimamente ligada à utilização dos movimentos do quotidiano em anos 60, pelos bailarinos-coreógrafos Yvonne Rainer e Steve Paxton, entre outros) permitiria que o olhar se recentrasse sobre o corpo. Ao mesmo tempo, e na sequência das experiências realizadas no âmbito da actividade daquele experiencias radis, adoptando novos palos, 

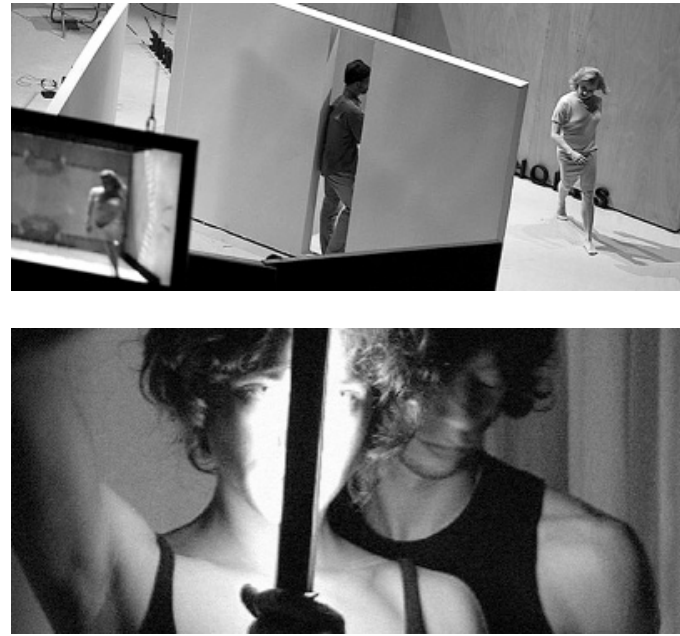

que tanto liga quanto separa; é na verdade extraordinário como Horta utiliza o dispositivo tecnológico na construção da falha - como ele trabalha sobre a dimensão trágica da técnica -, dividindo o público em dois partidos e criando a possibilidade de escutar o outro ponto de vista.

\section{(2) Desmultiplicação de planos}

Os procedimentos anteriormente referidos incluiam uma lógica de desmultiplicação de planos, que se encontra também, por exemplo, num dos coreógrafos mais marcantes do século XX, Merce Cunningham ${ }^{6}$. A tecnologia nomeadamente a utilização de hardware e software informáticos combinada com a câmara vídeo - tem, no conjunto da obra deste coreógrafo norte-americano, uma importância indiscutível. Para referir uma peça, Biped, de 1999, constitui um trabalho que funciona com e sobre séries de ecrãs translúcidos e que balança entre a figuração e a abstracção. Num outro criador contemporâneo, William Forsythe ${ }^{7}$, encontra-se também uma espécie de desconstrução arquitectónica do espaço cénico. Por exemplo, em Kammer Kammer (2000), ele utiliza um dispositivo de múltiplas projecções sobre ecrãs-praticáveis que são inteligentemente deslocados pelo espaço cénico; narradora e personagens aparecem "indiferentemente" no espaço físico do palco e no espaço projectado, prosseguindo uma narrativa que flutua entre o tangivel e o intangível e instaurando a ambiguidade na recepção.

\section{(3) Queda e vertigem}

0 espectador é assim conduzido frequentemente da impressão de ambiguidade à sensação de queda, sublinhada tanto pelos recursos técnicos utilizados, nomeadamente pelos efeitos de projecção, como também pela experimentação de um tipo de movimento que provém de disciplinas como o teatro físico e as artes marciais. A utilização frequente do turbilhão, do voltejo, do desequilíbrio, particularmente na dança contemporânea, enfatizam, na leitura de Virilio, a sensação de vertigem. (Virilio s.d.) É interessante - e é também Virilio quem o faz notar - a utilização de similares estratégias gráficas na banda desenhada sobretudo para representar as viagens no tempo.

Um dos coreógrafos mais impressivos, neste ponto, tem sido Wim Vandekeybus ${ }^{8}$. Em Blush, por exemplo, ele faz implantar em palco um sistema de ecrãs onde são projectados filmes de ambientes subaquáticos. Os performers movem-se energicamente no palco, rodopiam em vertigens e caem a todo o instante. Em certos momentos mergulham nos ecrãs. 0 público pode nesses momentos ver os corpos dos performers dentro do filme, como habitantes dos ambientes líquidos. Pouco depois, eles reaparecem no espaço seco do palco, para logo regressarem à queda e à vertigem. As imagens projectadas funcionam, pois, como se estivessem constantemente a engolir e a vomitar os corpos reais dos performers. A relação entre o mundo real e o mundo virtual das projecções torna-se ambivalente, para tanto contribuindo a sincronização entre a projecção e a coreografia. Em outro criador contemporâneo, Hiroaki Umeda, o sistema de projecções permite instaurar um lugar de imersão, em que o espectador julga mergulhar, ao mesmo tempo que acompanha a agilidade hipnótica do corpo do performer ao som de composições digitais.

Os exemplos não teriam que ficar por aqui e não devem ser apreciados como meras ilustrações daquilo que designei como tecnologia do abismo. Na verdade, muitas destas peças são atravessadas por um experimentalismo que, em última análise, interroga o próprio lugar da vertigem. Interrogação que é finalmente e também um questionamento sobre a função contemporânea da tecnologia e sobre o lugar do corpo.

0 que se passa então com o corpo? A resposta pode ser: anteriormente habitante de paisagens imaginárias, 0 corpo tornou-se ele próprio um produtor de espaços fragmentados, assim como o lugar de reunificação e entendimento de um mundo talvez irremediavelmente descontinuado.

\section{Referências bibliográficas}

BOUCHER, Marc (2004), "Kinetic Synaesthesia: Experiencing Dance in Multimedia Scenographies", Contemporary Aesthetics (www.contempaesthetics.org/newvolume/pages/article.php?articlel $D=235$, última consulta em Junho de 2008)

DIXON, Steve (2007), Digital Performance:A History of New Media in Theater, Dance, Performance Art, and Installation, Cambridge (Massachusetts) \&t London, MIT Press.

GIANNACHI, Gabriella (2004), Virtual Theatres: An Introduction, London \& New York, Routledge.

GINOT, Isabelle / MICHEL, Marcelle (2002), La Danse au XXe siècle, Paris, Larousse.

SCHIPHORST, Thecla (1997), Body Noise: Subtexts of Computer and Dance, v. http://www.art.net/ dtz/schipo3.html (última consulta em Agosto de 2008).

SCHLEMMER, Oskar (1978) "L'homme et la figure d'art: Mensch und Kunstfigur" [1925], in Théatre et Abstraction (L'Espace du Bauhaus), Paris, L'Âge d'Homme.

TOWNSEND, Julie (2001) "Alchemic Visions and Technological Advances: Sexual Morphology in Loïe Fuller's Dance", in Jane C. Desmond (ed.). Dancing Desires: Choreographing Sexualities on \& off the Stage, Madison, Wisconsin, The University of Wisconsin Press.

VIRILIO, Paul (s. d.) "Gravitational Space", in Traces of Dance: Drawings and Notations of Choreographers, Paris, Édition Dis Voir. 